\title{
Ontologi Kristus dan Hubungannya dengan Soteriologi
}

\author{
Yohanes Verdianto \\ Fakultas Teologi, Universitas Halmahera, Maluku Utara \\ yohanesvd@uniera.ac.id
}

\begin{tabular}{l}
\hline Article History \\
Received: \\
02 September 2020 \\
Revised: \\
03 November 2020 \\
Accepted: \\
29 November 2020 \\
\hline \\
Keywords \\
(Kata kunci): \\
Christology; \\
divine of Jesus; \\
humanity of Jesus; \\
Jesus Christ; \\
nature of Jesus; \\
soteriology; \\
keilahian Yesus; \\
kemanusiaan \\
Yesus; \\
kodrat Yesus; \\
Kristologi; \\
Soteriologi; \\
Yesus Kristus \\
D0l: \\
http://dx.doi.org/10. \\
$33991 /$ epigraphe.v4i1.200 \\
\end{tabular}

Article History

Received:

02 September 2020

Revised:

03 November 2020

Accepted:

29 November 2020

Keywords

(Kata kunci):

Christology;

divine of Jesus

Jesus Christ; nature of Jesus; soteriology;

keilahian Yesus,

emanusiaan

kodrat Yesus;

Kristologi;

Soteriologi;

\begin{abstract}
Controversies regarding Christology have occurred for centuries from the post-apostolic era to the present day, which the main controversy lies on the nature of Christ, and not in the function of Christ. This article aims to find out the nature of Christ related to soteriology, so that we can be sure that Jesus is the Savior that is fitting for human being. This is a qualitative approached article using a descriptive historical and documentary research method. By considering a Bible reading on Hosea 13:4 explained that there is no Savior beside God, thus only divine perfect being could be a perfect offering to redeem human being. Both divinity and humanity is needed for Christ to be an effective Savior because the Bible presents for Christ to be substitutionary sacrifice, to unite with humanity, and for him to be humanities' representative as the second Adam, to be their example and finally to be their mediator and priest.
\end{abstract}

\begin{abstract}
Abstrak
Kontroversi mengenai Kristologi telah terjadi selama berabad-abad dari era pasca-apostolik hingga saat ini, di mana isu utama adalah pada sifat Kristus, bukan pada fungsi Kristus. Kontroversi tentang kodrat Kristus selama inkarnasi-Nya selalu terkait dengan fungsi-Nya sebagai Juruselamat. Tulisan ini bertujuan untuk mengetahui sifat Kristus yang berkaitan dengan soteriologi, sehingga dapat dipastikan bahwa Yesus adalah Juruselamat yang cocok untuk manusia. Artikel ini merupakan pendekatan kualitatif yang menggunakan metode deskriptif historis serta penelitian dokumenter. Dengan mempertimbangkan pembacaan pada Hosea 13:4 yang menjelaskan bahwa tidak ada Juruselamat selain Tuhan, maka hanya sosok ilahi yang sempurna yang bisa menjadi persembahan sempurna untuk menebus manusia. Baik keilahian dan kemanusiaan diperlukan bagi Kristus untuk menjadi Juruselamat yang efektif karena Alkitab menyajikan bagi Kristus sebagai korban pengganti, untuk bersatu dengan umat manusia, dan baginya untuk menjadi perwakilan umat manusia sebagai Adam kedua, untuk menjadi teladan mereka dan akhirnya menjadi mediator dan imam mereka.
\end{abstract}

\section{Pendahuluan}

Sepanjang sejarah Kekristenan, dari era pasca-rasuli hingga saat ini, kontroversi mengenai Kristologi tidak pernah benar-benar berakhir. Banyak diskusi dan ketidaksepakatan tentang ontologi Kristus, terutama selama abad ke-4 dan ke-5. Mungkin dapat dikatakan bahwa pembagian yang paling kontroversial dan sekaligus paling diakui dalam Kristologi adalah Kristologi ontologis. Kristologi ontologis lebih mementingkan penegasan siapa Yesus;- identitas-Nya atau kodrat-Nya. ${ }^{1}$ Mungkin, dengan cara paling sederhana

\footnotetext{
${ }^{1}$ Alister E. McGrath, Studies in Doctrine (Grand Rapids, MI: Zondervan, 1997), 64.
} 
dapat dikatakan bahwa ini adalah studi tentang keberadaan Yesus, tentang kodrat-Nya, yaitu keilahian dan kemanusiaan-Nya. Di sisi lain, ada juga kristologi fungsional yang menekankan pada apa yang Yesus lakukan (fungsi-Nya) lebih daripada siapa Dia (wujud, kodrat). ${ }^{2}$

Dalam beberapa waktu belakangan ini, ada kecenderungan untuk membagi keduanya, namun, Alister McGrath dengan tepat mencatat bahwa walaupun ada perbedaan yang jelas antara Kristologi ontologis dan fungsional, ada juga hubungan yang erat antara keduanya dan bahwa cara berpikir keduanya tentang Yesus pada dasarnya adalah sama dalam hal hasil praktisnya, Dia menyatakan, "If Jesus is God, then he acts as God and for God. And if Jesus acts as God and for God, then all intents and purposes he is God. And if Jesus acts as God and for God, then all intents and purposes he is God."’3 Pertentangan yang paling sering terjadi adalah terkait dengan keselamatan, bagaimana melihat Kristologi dari dua sisi; atas dan bawah. ${ }^{4}$ Selain ada beberapa tanggapan kritis yang juga dilakukan terhadap rumusan "Kristologi" Saksii Yehuwa. ${ }^{5}$ Pandangan tersebut hampir selaras, ingin memperlihatkan bagaimana pertentangan mengenai isu Kristologi selalu menjadi sesuatu yang menarik dan unik.

Namun demikian, beberapa pembahasan diusulkan untuk memahami Kristologi secara komprehensif, dengan melihatnya dari beberapa penulis kitab Perjanjian Baru, seperti dalam perspektif Injil Lukas ${ }^{6}$, Injil Yohanes ${ }^{7}$, hingga tulisan-tulisan Paulus. ${ }^{8}$ Artikel ini akan berusaha untuk menemukan hubungan antara landasan ontologis-kodrat Kristus dan hubungannya dengan fungsi Kristus sebagai Juruselamat. Untuk membuat rrumusan masaalah lebih sederhana, pertanyaan pnelitian-nya adalah: Mengapa Yesus perlu (harus) ilahi dan manusia untuk menjadi Juruselamat yang efektif?

Untuk menjawab pertanyaan ini sangat penting bagi pemahaman kita tentang hubungan antara kodrat Kristus dan pekerjaan-Nya. Bahkan mungkin sedikit banyak menyelesaikan masalah pennggabungan dua kodrat dalam Kristus karena seperti yang akan dibuktikan nanti dalam makalah ini, karena perlu bagi Kristus untuk menjadi manusia dan Ilahi, penggabungan dua kodrat juga merupakan keharusan bagi Kristus untuk menjadi Juruselamat yang sempurna bagi manusia.

\section{Metode Penelitian}

Penelitian ini merupakan kajian kualitatif dengan menggunakan data pustaka (literatur), baik dari jurnal maupun referensi lain terkait tema Kristologi. Metode yang digunakan

${ }^{2}$ Millard J. Erickson, Christian Theology (Grand Rapids, MI: Baker, 1998), 715.

${ }^{3}$ McGrath, Studies in Doctrine, 64.

${ }^{4}$ Robert Pangaribuan, "Menyikapi Perbedaan Pandangan Christology from Above and Christology from Below," SOTIRIA (Jurnal Theologia dan Pendidikan Agama Kristen) 2, no. 1 (2019): 16-29.

${ }^{5}$ Pangeran Manurung, "Studi Eksegetis Yohanes 1: 1-18 Sebagai Apologetik Terhadap Kristologi Saksi Yehuwa," Journal Kerusso 1, no. 2 (2016): 1-41. Band. Eliman Eliman, "Kritik Dan Analisa Terhadap Pandangan Saksi Yehuwa Tentang Keilahian Yesus," KURIOS (Jurnal Teologi dan Pendidikan Agama Kristen) 3, no. 1 (2018): 22-39.

${ }^{6}$ Frans Setyadi Manurung, "Teologi Keramahan Allah: Sebuah Pembacaan Kristologi Lukas," GEMA TEOLOGIKA: Jurnal Teologi Kontekstual dan Filsafat Keilahian 3, no. 2 (2018): 185-206.

${ }^{7}$ Roy Martin Simanjuntak, "Kristologi Dalam Injil Yohanes," JURNAL TERUNA BHAKTI 1, no. 2 (2019): 75-86.

${ }^{8}$ David Alinurdin, "Apakah Keilahian Yesus Merupakan Ciptaan Paulus?: Penyelidikan Terhadap Tradisi Gereja Purba Dalam Surat Paulus” (2010). 
adalah deskriptif historis dan argumentatif filosofis, serta metode bantu komparatif untuk membandingkan beberapa pemikiran terkait kristologi yang berkembang dari masa ke masa. Penggunaan metode ini dianggap yang paling memadai untuk dapat menampilkan sejarah kontroversi secara historis tentang Kristologi dan mengaitkannya secara ontologis dalam pemikiran teologis untuk memahami ksatuan kodrat Yesus sebagai Juruselamat.

\section{Kontroversi Kristologi dalam Sejarah}

Dari sejarah Gereja yang paling awal, selalu ada kontroversi mengenai Kristologi khususnya mengenai sifat Kristus. Sulit bagi orang Kristen masa awal untuk menerima bahwa Yesus adalah ilahi dan manusia, mereka menolak kemanusiaan Kristus atau keilahian Kristus. Kelompok-kelompok seperti Ebionites, Alogi, dan Dynamic Monarchian menyangkal keilahian Kristus, sementara para Docetics, dan Modalists menolak kemanusiaan-Nya. ${ }^{9}$ Misalnya, Ebionites adalah kelompok Kristen yang mematuhi hukum Yahudi dan mereka hanya menggunakan Injil Matius mengenai kelahiran Yesus secara biasa saja. Mungkin karena kecenderungan monoteistik mereka yang kuat, mereka menolak Yesus sebagai Allah tetapi menegaskan bahwa Ia hanyalah seorang nabi. ${ }^{10}$ Mereka juga memahami Yesus sebagai manusia biasa yang dibenarkan karena ketaatan pada hukum Taurat dan dengan demikian memenuhi syarat untuk menjadi seorang Mesias. ${ }^{11}$

Di sisi lain, mereka yang menolak kemanusiaan Kristus seperti Docetist dan Modalist percaya bahwa Kristus tidak memiliki tubuh yang sebenarnya, ia hanya muncul atau tampaknya memiliki tubuh, kaum Modalist akan mengklaim bahwa Allah muncul dalam bentuk yang berbeda di waktu yang berbeda, dan di contoh ini, Ia muncul dalam bentuk manusia tetapi tidak memiliki tubuh yang sebenarnya. ${ }^{12}$ Sedangkan bagi para Docetist masalahnya terletak pada isu tentang keselamatan-karena jika Kristus mati, maka Dia bukanlah Allah; dan kalau Dia adalah Allah, maka Dia tidak dapat mati. Jelas di sini terlihat bahwa permasalahan yang muncul dalam Kristologi adalah selalu berhubungan dengan soteriologi. Dengan demikian, keselamatan adalah inti utama dalam kontroversi-kontroversi ini.

Ada banyak kontroversi Kristologis dalam sejarah, tetapi bagian ini hanya akan menyoroti kontroversi besar dan hubungannya dengan soteriologi. Tujuan utama dari diskusi ini adalah untuk menunjukkan bahwa pertanyaan soteriologis terletak pada fondasi dari kontroversi-kontroversi ini dan sedikit banyak menyebabkan penolakannya oleh dewan gereja atas dasar masalah soteriologis mereka. Di antara banyak kontroversi ini, makalah ini hanya akan membahas dua kontroversi yang pernah terjadi dalam sejarah gereja sehubungan dengan Kristologi dan hubungannya dengan soteriologi. Adapun kedua kontroversi itu adalah: Arianisme, dan Apollinarianisme. Masalah

\footnotetext{
${ }^{9}$ Louis Berkhof, The History of Christian Doctrines (Grand Rapids, MI: Eerdmans, 1949), 106.

${ }^{10}$ David Noel Freedman, The Anchor Bible Dictionary (New York, NY: Doubleday, 1996), 261.

${ }^{11}$ Stanley J. Grenz, Theology for the Community of God (Grand Rapids, MI: Eerdmans, 1994): 247. Kaum Ebionites berkata bahwa, "understood Jesus as a mere man who by scrupulous observance of the law was justified and thereby became the Messiah."

12 Bengt Hagglund, History of Theology (St. Louis, MO: Concordia, 1999), 72.
} 
Arianisme adalah tentang keilahian Kristus, sedangkan Apollinarianisme adalah tentang kemanusiaan Kristus.

\section{Arianisme}

Kelompok ini diambil dari nama pendirinya, Arius. Arius adalah seorang presbiter yang populer di Gereja Alexandria (meninggal $335 \mathrm{M}$ ). Arius menyangkal ke-Ilahian penuh Kristus dan dia berpendapat berpendapat bahwa,

Son of God was not eternal but created before the ages by the Father from nothing as an instrument for the creation of the world; He was therefore not God by nature, but a creature, and so susceptible of change, even though different from all other creatures in being the one direct creation of God. ${ }^{13}$

Arianisme memiliki kepercayaan monoteistik yang sangat kuat, konsepsi utamanya adalah bahwa Allah, Bapa adalah satu-satunya yang tidak tercipta di seluruh alam semesta, Dia adalah satu-satunya makhluk sejati yang memiliki sifat ke-Tuhanan dan sifat ini tidak dapat dibagi. ${ }^{14}$ Karena itu, sementara Anak atau Logos adalah ciptaan yang sempurna, ia bukanlah wujud yang benar-benar ada. Pasti ada titik waktu tertentu ketika Anak muncul atau menjadi ada dan dengan demikian membentuk slogan Arianisme yang terkenal, "There was a time when he was not."15

Meskipun kelihatannya masalah ini berasal dari perspektif ontologis, namun esensi dari perdebatan ini sebenarnya adalah soteriologis. Misalnya, Athanasius, pembela yang kuat dari kredo Nicea dan lawan utama Arius mengatakan bahwa Arianisme menyangkal keilahian Yesus dan dengan demikian mereka menyangkal kematian Yesus yang memiliki nilai keselamatan. Athanasius berkata bahwa "he was convinced that Arianism denied the lord's divinity and voided Jesus' death of salvific value."16 Ia berpendapat bahwa hanya oknum yang benar-benar Allah yang dapat membawa keselamatan bagi umat manusia. Dalam tulisannya, Four Discourse Against the Arians, Athanasius berargumen bahwa,

Again, if the Son were a creature, man had remained mortal as before, not being joined to God; for a creature had not joined creatures to God, as seeking itself one to join it; nor would a portion of the creation have been the creation's salvation, as needing salvation itself. ${ }^{17}$

Dalam argumennya ini Athanasius menegaskan kepada Arianisme bahwa seandainya Yesus hanyalah manusia, maka manusia tetap saja fana seperti sebelumnya, dan tidak dapat disatukan dengan Allah, karena tidak mungkin manusia biasa dapat menyatukan manusia lainnya dengan Allah. Tentu saja kematian Yesus pun sia-sia, karena tidak dapat membawa manusia ke hadirat Allah. Namun karena Yesus juga adalah Allah, maka kematian-Nya dapat menjembatani manusia fana dengan Allah yang kekal.

\footnotetext{
${ }^{13}$ F. L. Cross and Elizabeth A. Livingstone, The Oxford Dictionary of the Christian Church, $3^{\text {rd }}$ ed. rev. (New York, NY: Oxford University Press, 2005), 100.

${ }^{14}$ Erickson, Christian Theology, 712.

${ }^{15}$ Ibid.

${ }^{16}$ John E. Meyer, “Athanasius' Usage of Paul in his Doctrine of Salvation,” Vigiliae Christianae 52 (1998), 149.

${ }^{17}$ Athanasius Four Discourses Against the Arians 2.69, dalam Nicene and Post Nicene Fathers (NPNF) 4.286, Philip Schaff, trans.
} 


\section{Apollinarianisme}

Setelah konfirmasi formula homoousios ${ }^{18}$ pada Konsili Nicea, dan setelah penolakan Arianisme oleh gereja, pertanyaan besar berikutnya yang harus dihadapi oleh gereja adalah bagaimana fakta bahwa Logos adalah satu substansi dengan Bapa dapat digabungkan dengan fakta bahwa Logos muncul dalam bentuk manusia? Di antara orang pertama yang memiliki masalah ini adalah Apollinaris. ${ }^{19}$ Meskipun dia adalah pendukung kredo Nicea, dia tidak puas dengan hanya begitu saja menerima gagasan bahwa Logos, sehubungan dengan kodrat Ilahi, memiliki substansi yang sama dengan Bapa. Dia beralasan bahwa kemanusiaan Kristus harus memiliki kualitas Ilahi, kalau tidak, maka kehidupan dan pekerjaan Kristus tidak akan bisa membawa keselamatan. ${ }^{20}$ Dasar utama pandangan Apollinarisme adalah tentang masalah keselamatan.

Menurut Apollinarisme ${ }^{21}$, apa yang Yesus kenakan ketika Dia menjadi seorang manusia, bukanlah seluruh kemanusiaan manusia, tetapi hanya daging, yaitu tubuh saja. Secara fisik, Yesus adalah manusia, namun secara psikologis, Dia bukanlah manusia. Singkatnya, Yesus adalah manusia yang memiliki jiwa Ilahi. Erickson menjelaskan pandangan Apollinarisme sebagai berikut,

Jesus took was not the whole of humanity, but only flesh, that is, the body. This flesh could not, however, be animated by itself. There had to be a "spark of life" animating it. This was the divine Logos; it took the place of the human soul. Thus, Jesus was human physically, but not psychologically. He had a human body, but not a human soul. His soul was divine. ${ }^{22}$

Gagasan tentang kodrat Kristus ini menciptakan penolakan dan kritik tersendiri. Sebagian alasan penolakan mungkin karena Apollinarisme menyatakan bahwa meskipun Yesus adalah manusia, ia agak berbeda dari manusia lainnya karena Ia tidak memiliki jiwa manusia. Hanya ada satu pusat kesadaran di dalam diri-Nya yang Ilahi dan karena itu Ia tidak memiliki kehendak manusia, karena tidak mungkin ada dua jiwa dalam satu tubuh manusia Yesus Kristus. Pribadi-Nya sepenuhnya dikendalikan oleh kehendak Ilahi. Dan karena Yesus tidak memiliki kehendak manusia, maka Dia tidak bisa berbuat dosa. ${ }^{23}$

Pertanyaan soteriologis sehubungan dengan pandangan Apollinarisme ini adalah bagaimana mungkin Yesus bisa menjadi Juruselamat manusia, jika Dia tidak memiliki pikiran dan jiwa manusia. Dan terlebih lagi, Ia tidak dapat menjadi teladan manusia jika Ia tidak memiliki kehendak manusia. Gregorius dari Nazianzus, seorang uskup di Constantinople menyatakan dengan jelas argumen ini ketika dia berkata bahwa, "If anyone has put his trust in him as a man without a human mind, he is himself devoid of mind

\footnotetext{
${ }^{18}$ Dalam Kekristenan, Homoousios adalah terminologi kunci terhadap doktrin Kristologi yang diformulasikan pada konsili gereja pertama yang diadalan di Nicea pada tahun $325 \mathrm{M}$, untuk menegaskan bahwa Anak Allah dan Allah Bapa memiliki substansi yang sama. Lihat https://www.britannica.com/topic/homoousios.

${ }^{19}$ Hagglund, History of Theology, 89.

${ }^{20}$ Ibid.

${ }^{21}$ Apollinarisme adalah konsep Kristologi yang dicetuskan oleh Apollinaris dari Laodikea (meninggal 390).

${ }^{22}$ Erickson, Christian Theology, 731.

${ }^{23}$ Ibid.
} 
and unworthy of salvation. For what he has not assumed he has not healed; it is what is united to his Deity that is saved." 24 Apollinaris tidak puas dengan pemahaman ortodoks dan kemudian dia membuat pertanyaan terutama berdasarkan pada landasan soteriologis, dia datang dengan memberikan pemahaman baru tentang kodrat Kristus. Namun gagasannya ini ditolak pada Konsili Gereja Kedua yang diadakan di Constantinople pada tahun $381 \mathrm{M}$.

\section{Pembahasan}

\section{Kodrat Kristus dan Keselamatan}

Seperti telah dijelaskan di atas bahwa kodrat Kristus dan keselamatan berhubungan erat dan saling memengaruhi. Mayoritas gereja Kristen sejak Konsili Chalcedon ${ }^{25}$ pada tahun $451 \mathrm{M}$ telah mengajarkan bahwa Kristus sepenuhnya Ilahi dan juga sepenuhnya manusia. Di satu sisi, penolakan terhadap ajaran selain ini didasarkan pada perlunya bagi Kristus untuk menjadi manusia dan Ilahi agar dapat menjadi Juruselamat. Bagian ini akan mencoba menjawab pertanyaan-Mengapa Yesus perlu sepenuhnya ilahi dan sepenuhnya manusia untuk menjadi Juruselamat yang efektif? Mengenai hal ini, Alkitab dalam Hosea 13:4 dengan jelas menyatakan bahwa tidak ada Juruselamat selain Allah. Hanya wujud sempurna Ilahi yang bisa menjadi persembahan yang sempurna untuk menebus manusia.

\section{Persatuan Dengan Kristus}

Robert Letham mengatakan bahwa, "the theme of union with Christ is vital to an understanding of what he has done. It is foundation to every aspect of our salvation." 26 Menurut Letham, persatuan dalam Kristus inilah yang menjadi dasar dari setiap aspek keselamatan umat manusia. Kunci untuk mengetahui persatuan ini adalah dari mengerti kodrat Kristus yang adalah Ilahi dan manusia. Lagi pula, hanya karena siapa Kristus itulah, sehingga kita dapat memiliki persatuan dengan Kristus. Persatuan ini adalah hubungan spiritual dan hubungan yang hidup antara pengikut Yesus Kristus dan Allah Trinitas yang didasarkan pada pekerjaan penyelamatan Kristus yang bekerja untuk menyatukan kembali manusia dengan diri-Nya. Hubungan ini adalah penyatuan jiwa antara manusia yang terbatas dan Allah yang tak terbatas. ${ }^{27}$ Dan yang lebih jelas lagi bahwa penyatuan ini tidak dapat dilakukan oleh manusia sendiri karena yang terbatas tidak mampu mengetahui yang tak terbatas, oleh karena itu Yesus yang Ilahi harus meng-ambil inisiatif dalam persatuan ini.

Bagaimana mungkin persatuan ini terjadi? Letham dengan tepat mengatakan bahwa "our union with Christ is grounded on his union with us. We can become one with him

\footnotetext{
${ }^{24}$ Gregory of Nazianzus, "An Examination of Apollinarius," dalam Henry Bettenson, Documents of the Christian Church (New York, NY: Oxford University Press, 2011), 45.

${ }^{25}$ Konsili ini menegaskan definisi ortodoks bahwa Yesus adalah sepenuhnya manusia dan sepenuhnya Allah, dua kodrat dalam satu pribadi.

${ }^{26}$ Robert Letham, The Work of Christ, Contours of Christian Theology (Downers Grove, IL: InterVarsity, 1993), 75.

${ }^{27}$ Bruce A. Ware, "Cur Deus Trinus? The Relation of the Trinity to Christ's Identity as Savior and to the Efficacy of his Atoning Death," The Southern Baptist Journal of Theology 10, no. 1: 48-56. Di sini, Ware berpendapat bahwa keberhasilan karya penebusan Kristus tergantung pada hubungannya dengan Bapa sebagaimana juga dengan Roh Kudus dan adalah mustahil tanpa hubungan dengan Allah Tritunggal ini.
} 
because he made himself one with us." ${ }^{28}$ Dalam Yohanes 1:1-3, 14 dan Ibrani 4:14-5: 10, dikatakan di sana bahwa persatuan Kristus dengan manusia terjadi dalam inkarnasiNya, di dalam diri-Nya menjadi manusia. Sederhananya, persatuan kita dengan Kristus dapat terjadi hanya karena kemanusiaan Kristus, sementara pada saat yang sama penyatuan kita dengan Allah Tritunggal hanya dapat terjadi karena kodrat Ilahi Kristus. Disatukan dengan Kristus sebagai hasilnya membawa kita dipersatukan dengan Allah sendiri yang merupakan tujuan utama dari rencana keselamatan. Dalam pengertian ini, kodrat Ilahi dan manusia dari Kristus adalah penting dalam konsep "persatuan dengan Kristus."

\section{Adam Kedua}

Konsep "Adam kedua," adalah identifikasi Perjanjian Baru yang umum untuk Yesus Kristus (Rm. 5:12-21). Yang benar-benar terjadi ini adalah aspek representatif dari Kristus dan juga kematian-Nya sebagai pengganti. Sama seperti Adam adalah wakil dari umat manusia, demikianlah Yesus sebagai Adam kedua juga merupakan wakil dari umat manusia. Meskipun mungkin ada beberapa kesamaan, Kettler menyebutkan perbedaan antara keduanya,

Despite the similarities, the Adam-analogy in Paul points out their difference as well in their likenesses. The difference in the Last Adam is that he is able to be the substitute for the faithlessness of humanity. Both Adams are representatives. Only the Last Adam can remove any place for the immorality and arrogance of the Corinthians to stand, by taking their place, not just in death, but in death and life, in the fullness of their humanity. ${ }^{29}$

Sangat jelas bahwa Kristus hanya bisa menjadi Adam kedua, jika Ia mengambil kodrat manusia. Dan dengan demikian, bagi Kristus untuk menjadi representatif sekaligus pengganti umat manusia, Ia harus menjadi manusia. Dalam pengertian ini, kemanusiaan Kristus diperlukan baginya untuk menjadi representatif dan pengganti yang efektif, dan dengan demikian menjadi seorang Juruselamat.

\section{Pekerjaan Pengantaraan dan Keimamatan Kristus}

Pekerjaan pengantaraan dan keimamatan Kristus mungkin merupakan salah satu elemen terpenting dalam pembahasan tentang kodrat Kristus dan keselamatan. Kitab Ibrani sangat kaya dalam diskusi ini. Jacobus Arminius berpendapat dari kitab ini bahwa hanya Kristus yang bisa menjadi imam dan perantara antara manusia yang berdosa dan Allah. Menurutnya, Kristus menjalankan dua fungsi sakral: fungsi pertama adalah persembahan atau pengorbanan diri-Nya kepada Allah sebagai penebusan yang sempurna dari dosa; yang kedua adalah pengantaraan-Nya bagi dosa-dosa umat-Nya. ${ }^{30}$ Dia sangat tegas menyatakan bahwa hanya Seorang dengan dua fungsi ini yang bisa menjadi imam dan pengantara manusia yang efektif. Pinson mengklarifikasi pandangan Arminius sebagai berikut,

\footnotetext{
${ }^{28}$ Letham, The Work of Christ, 77.

${ }^{29}$ Christian D. Kettler, "The Vicarious Humanity of Christ and the Reality of Salvation" (PhD diss., Fuller Theological Seminary, Pasadena, CA, 1986), 327.

${ }^{30}$ Matthew J. Pinson, "The Nature of Atonement in the Theology of Jacobus Arminius" Journal of Evangelical Theology 53/4 (December, 2010), 776.
} 
An angel could not qualify as a priest, because priests were to be representatives of humanity (Heb. 5:1) and the death of an angel could never serve as expiation for human sin. A human being "could not be found" to fulfill the priestly office, because human beings were sinners held captive under the "tyranny of sin and Satan." Because of this sinfulness, humans cannot approach God, "who is pure light," to make a sacrifice. Still, however, "the priest was to be taken from among men, and the oblation to God was to consist of a human victim." The divine wisdom determined that a human was required who had humanity in common with "his brethren," being "in all things tempted as they were" and thus "able to sympathize" with them in their sufferings. Yet this individual could not be under sin's dominion. Arminius here cites Heb. 7:26, which speaks of Jesus' being "born in the likeness of sinful flesh, and yet without sin. For such a high priest became us, who is holy, harmless, undefiled, and separate from sinners." For such a state of affairs to obtain, such a person must be conceived by the Holy Spirit. Moral purity, Arminius maintains, is only one qualification of this cosmic priest. The priest must be divine: "Therefore the Word of God, who from the beginning was with God, and by whom the worlds, and all things visible and invisible, were created, ought himself to be made flesh, to undertake the office of the priesthood, and to offer his own flesh to God as a sacrifice for the life of the world."

Singkatnya Arminius percaya bahwa Yesus harus menjadi manusia dan Ilahi untuk menjadi pengantara yang efektif, imam dan Juruselamat. Ide yang sama ini disampaikan oleh beberapa penulis lainnya. Misalnya, Oden mengatakan bahwa tidak ada mediasi antara Allah dan manusia tanpa menempatkan seorang pengantara yang mampu berempati dengan manusia biasa, namun di saat yang sama dia memiliki kodrat yang setara dengan Allah. Lengkapnya Oden mengatakan bahwa,

There can be no mediation between God and humanity without positing a mediator capable of empathy with ordinary humanity and of equal dignity with God (Phil. 2:6-11; Heb. 2:17-18). As human, he is capable of making intercession and sacrificial offering for humanity; as divine Son his act of sacrificial offering has infinite value to the Father (Heb. 4:15). ${ }^{31}$

Kolose 2:9 berkata bahwa, "Sebab dalam Dialah berdiam secara jasmaniah seluruh kepenuhan Ke-Allah-an." Kristus mengambil bagi diri-Nya sendiri manusia, agar ia dapat menjangkau manusia. Ke-Ilah-ian membutuhkan kemanusiaan; untuk diperlukan yang ilahi dan manusia untuk membawa keselamatan ke atas dunia. Keilahian membutuhkan manusia, agar manusia dapat menyediakan saluran komunikasi antara Allah dan manusia. Kristus tidak hanya harus menjadi makhluk Ilahi yang tidak berdosa tetapi juga manusia untuk mengidentifikasi diri-Nya dengan mereka. Pentingnya kedua sifat ini dalam kaitannya dengan keselamatan ditunjukkan oleh Anselmus dari Canterbury pada konteks penebusan, ia menyatakan bahwa, "It is necessary that a God-Man should pay for sin, since, no one can pay except God, and no one ought to pay except man." 32

${ }^{31}$ Thomas C. Oden, Classic Christianity: A Systematic Theology (New York, NY: Harper One, 1992), 316.

${ }^{32}$ Anselm, Cur Deus Homo 2.6. dikutip dalam Bruce A. Ware, "Cur Deus Trinus? The Relation of the Trinity to Christ's Identity as Savior and to the Efficacy of his Atoning Death" The Southern Baptist Journal of Theology 10, no. 1:48. 


\section{Kesimpulan}

Artikel ini membahas Kristologi ontologis, yaitu kodrat Kristus sebagai manusia sepenuhnya dan sepenuhnya Allah, dan hubungannya dengan masalah soteriologi. Ada dua kesimpulan. Pertama, dalam inti masalah Kristologi terletak pertanyaan soteriologi. Pandangan Kristologi, khususnya tentang kodrat Kristus, mempengaruhi pandangan mereka tentang keselamatan yang ditemukan dalam debat historis Arianisme dan Apollinarianisme. Kedua, baik keilahian dan kemanusiaan diperlukan agar Kristus menjadi Juruselamat yang efektif, karena Alkitab menjelaskan tentang Kristus untuk menjadi korban pengganti, untuk dipersatukan dengan umat manusia, dan bagi-Nya untuk menjadi perwakilan umat manusia sebagai Adam kedua, untuk menjadi teladan mereka dan akhirnya untuk menjadi perantara dan imam mereka.

\section{Referensi}

Alinurdin, David. “Apakah Keilahian Yesus Merupakan Ciptaan Paulus?: Penyelidikan Terhadap Tradisi Gereja Purba Dalam Surat Paulus" (2010).

Anselm of Canterbury, Cur Deus Homo 2.6. dikutip dalam Bruce A. Ware, "Cur Deus Trinus? The Relation of the Trinity to Christ's Identity as Savior and to the Efficacy of his Atoning Death" The Southern Baptist Journal of Theology 10, no. $1: 48$.

Athanasius Four Discourses Against the Arians 2.69, dalam Nicene and Post Nicene Fathers (NPNF) 4.286, Philip Schaff, trans.

Berkhof, Louis. The History of Christian Doctrines (Grand Rapids, MI: Eerdmans), 1949.

Bettenson, Henry. Documents of the Christian Church (New York, NY: Oxford University Press), 2011.

Cross, F. L. and Elizabeth A. Livingstone, The Oxford Dictionary of the Christian Church, $3^{\text {rd }}$ ed. rev. (New York, NY: Oxford University Press), 2005.

Eliman, Eliman. "Kritik Dan Analisa Terhadap Pandangan Saksi Yehuwa Tentang Keilahian Yesus." KURIOS (Jurnal Teologi dan Pendidikan Agama Kristen) 3, no. 1 (2018): 22-39.

Erickson, Millard J. Christian Theology (Grand Rapids, MI: Baker), 1998.

Freedman, David Noel. The Anchor Bible Dictionary (New York, NY: Doubleday), 1996.

Gregory of Nazianzus, "An Examination of Apollinarius," dalam Henry Bettenson, Documents of the Christian Church (New York, NY: Oxford University Press), 2011.

Grenz, Stanley J. Theology for the Community of God (Grand Rapids, MI: Eerdmans), 1994.

Hagglund, Bengt. History of Theology (St. Louis, MO: Concordia), 1999.

https://www.britannica.com/topic/homoousios.

Kettler, Christian D. "The Vicarious Humanity of Christ and the Reality of Salvation" (PhD diss., Fuller Theological Seminary, Pasadena, CA), 1986.

Letham, Robert. The Work of Christ, Contours of Christian Theology (Downers Grove, IL: InterVarsity), 1993.

Manurung, Frans Setyadi. "Teologi Keramahan Allah: Sebuah Pembacaan Kristologi Lukas." GEMA TEOLOGIKA: Jurnal Teologi Kontekstual dan Filsafat Keilahian 3, no. 2 (2018): 185-206.

Manurung, Pangeran. "Studi Eksegetis Yohanes 1: 1-18 Sebagai Apologetik Terhadap Kristologi Saksi Yehuwa.” Journal Kerusso 1, no. 2 (2016): 1-41. 
McGrath, Alister E. Studies in Doctrine (Grand Rapids, MI: Zondervan), 1997.

Meyer, John E. "Athanasius' Usage of Paul in his Doctrine of Salvation," Vigiliae Christianae 52 (1998), 149.

Oden, Thomas C. Classic Christianity: A Systematic Theology (New York, NY: Harper One), 1992.

Pangaribuan, Robert. "Menyikapi Perbedaan Pandangan Christology from Above and Christology from Below." SOTIRIA (Jurnal Theologia dan Pendidikan Agama Kristen) 2, no. 1 (2019): 16-29.

Pinson, Matthew J. "The Nature of Atonement in the Theology of Jacobus Arminius" Journal of Evangelical Theology 53/4 (December, 2010), 776.

Simanjuntak, Roy Martin. "Kristologi Dalam Injil Yohanes.” JURNAL TERUNA BHAKTI 1, no. 2 (2019): 75-86.

Ware, Bruce A. "Cur Deus Trinus? The Relation of the Trinity to Christ's Identity as Savior and to the Efficacy of his Atoning Death," The Southern Baptist Journal of Theology 10, no. 1: 48-56. 